\title{
Factors Associated with Antiretroviral Treatment Adherence among Adult Patients in Wolaita Soddo Hospital
}

\author{
Amsalu Alagaw ${ }^{1}$, Wanzahun Godana ${ }^{1 *}$, Mohammed Taha² and Tariku Dejene ${ }^{2}$ \\ ${ }^{1}$ Department of Public Health, College of Medicine and Health Sciences, Arba Minch University, Arba Minch, Ethiopia \\ ${ }^{2}$ School of Public Health, College of Health Sciences, Jimma University, Jimma, Ethiopia
}

\begin{abstract}
Background: HIV a major challenge to the whole world since the last quarter of $20^{\text {th }}$ century but has become a member of a manageable chronic disease since the advent of ARV drugs. The non-adherence to Antiretroviral Therapy is an emerging major challenge to AIDS care.

Objective: To assess factors associated with adherence among AIDS patients receiving Antiretroviral Therapy at Wolaita Soddo Hospital, Southern Ethiopia.

Method: A cross sectional study was carried out at Wolaita Soddo Hospital from April 15 to May 15, 2012 E.C. Three hundred and fifty seven HIV/ AIDS patients were involved in the study. The collected data were entered in Epi Info version 3.5.3. Data analyses were done using SPSS for windows version 16.0. Multivariable analyses were applied to identify the relative effect of explanatory variables on the dependent variable.

Results: Multi-method adherence assessment consisting of self-report, monthly dispense schedule and dietary requirements, were used to measure adherence and the average adherence rate was $74.4 \%$. Multivariate logistic regression analysis showed that, with whom a subject lives (Adjusted Odds Ratios $(A O R)=4.943,1,(2.168-11.270)$ ), depression (AOR=2.221,1,(1.093-4.515)), and having inadequate diet to take with ART (AOR=2.229,1,(1.034-4.807)), were independent predictors of dose adherence.
\end{abstract}

Conclusions: In conclusion living with a partner, having no depression and having no food scarcity to take with ART have association with adherence to ART regimens.

\section{Keywords: HIV; Adherence; Factors}

\section{Background}

Worldwide an estimated 33 million people are living with HIV. Since the beginning of the HIV epidemic in 1981, 25 million people have died of AIDS globally. Every day, there are 7,400 new HIV infections, $96 \%$ of which are in the low-and middle-income countries. Africa disproportionately bears the burden of the HIV/AIDS pandemic. Although only $11 \%$ of the world's population lives in Africa, roughly $67 \%$ of those living with HIV/AIDS are in Africa. In Africa, there were 22.4 million people living with HIV and 1.9 million new HIV infections in 2008 [1,2].

According to the most recent data from the Joint United Nations Program on HIV/AIDS and National projections estimate approximately 1.1 million Ethiopians are living with HIV and prevalence increased slightly to 2.3 percent [3]. In 2009 alone, 43,130 new HIV patients were started on Anti Retroviral Treatment (ART). Likewise the total number of people ever enrolled to chronic HIV care reached to 435,150 by the end of 2009 [1]. With the advent of ART, HIV/AIDS is becoming a chronic disease; therefore adherence to HIV medication is an extremely important but complicated process that needs dedication from patients, sympathetic support from the society, and high level of care from health care professionals [4].

Worldwide, regardless of the illness or treatment many people do not take their medications correctly [5]. A study in Brazil showed that the cumulative incidence of non adherence to be $36.9 \%$ [6]. Adherence among patients in Soweto, South Africa was $88 \%$ In Cape Town; $63 \%$ of patients maintained adherence levels of $90 \%$ [7]. Consistent factors for poor adherence include, stress, substance use, regimen complexity, self efficacy for medication taking and depression Social support have also been consistently associated with decreased adherence and a patient who doesn't have social support is less likely to continue their treatment with optimal requirement [8].

On aggregate, non-adherence to ART is estimated at between 50 $80 \%$ in different social and cultural settings [9]. With optimal adherence rates, studies by Lewis, Rao and others have demonstrated that ART can suppress the viral load to undetectable levels, boost the immune system by increasing the number of CD- 4 cells, and improve the quality of life of People Living with HIV/AIDS (PLWHA) [9]. Since its introduction about 10 years ago, ART has progressed from a single therapy, to double therapy, and finally to the current combination therapy commonly known as Highly Active Antiretroviral Therapy (HAART). This development was necessitated by the desire to reduce the number of pills taken by the patient in order to foster adherence. This was borne out of the realization that adherence rates were inversely proportional to the number of pills, capsules or tablets necessary for treatment [10].

Despite patients' understanding the consequences of nonadherence to medication, adherence rates were sub optimal [6]. Longterm adherence interventions are needed for durable effect, particularly

*Corresponding author: Wanzahun Godana, Department of Public Health College of Medicine and Health Sciences, Arba Minch University, Arba Minch Ethiopia, Tel: 251913689198; E-mail: wanzanati2011@gmail.com

Received November 04, 2013; Accepted December 11, 2013; Published December 13, 2013

Citation: Alagaw A, Godana W, Taha M, Dejene T (2013) Factors Associated with Antiretroviral Treatment Adherence among Adult Patients in Wolaita Soddo Hospital. J Trop Dis 1: 125. doi: 10.4172/2329-891X.1000125

Copyright: $\odot 2013$ Alagaw A, et al. This is an open-access article distributed unde the terms of the Creative Commons Attribution License, which permits unrestricted use, distribution, and reproduction in any medium, provided the original author and source are credited. 
in chronic diseases such as HIV. Antiretroviral therapy lowers viral load only when treatment regimen is fully adhered to. Human Immuno Deficiency Virus (HIV) poses a unique challenge due to its rapid replication and mutation rates hence very high levels of adherence (greater than 95\%) are required to achieve long-term suppression of viral load [11].

A study conducted in Jimma University Specialized Hospital on predictors of ART adherence among HIV infected patients Selfreported dose adherence in the study area was $94.3 \%$. But, the rate considering the combined indicator (dose, time and food) was $75.7 \%$ [12]. Many studies have observed that self-reporting over-estimates adherence, as patients may report to be perfectly adhering when, in actual sense, they are not [11-13]. Barriers related to daily schedules: disruptions in routine or having a chaotic schedule, finding HAART too inconvenient or difficult to incorporate and difficulties coordinating adherence with work, family or care giving responsibilities at home. A patient's behavior is the critical link between a prescribed regimen and treatment outcomes [14]. The objective of the study was to assess level of adherence and identify factors associated with adherence to ART among adult HIV patients.

\section{Methods and Materials}

The study was conducted in Wolaita Soddo hospital, which is one of hospitals in Wolaita soddo town from April 15/2012_May15/2012. The town is located in SNNPR $378 \mathrm{~km}$ south of Addis Ababa. Wolaita Soddo Hospital currently is in transition period to be Wolaita Soddo University hospital is serving in four major clinical fields i.e. Internal medicine, pediatrics, surgery and gynecology. There are also some minor specialized fields like dental care service. The Hospital serving thousands of HIV/AIDS patients since 2005 from rural and urban areas. There were 2400 HIV AIDS patients on follow up among which 1162 started ART treatment and on follow up. A cross sectional study was utilized with an internal comparison of adherence status among predictor variables.

The dependent variable in this study was adherence status to ARV treatment. (Adherence was measured by dose adherence; adhered were those who took greater than or equal to $95 \%$ of the prescribed drugs). In most studies, researchers assess adherence by indicators that measure the rate of follow up of dose of the drugs prescribed. But successful treatment with ART also includes adhering to dietary instructions that accompany many antiretroviral drugs [15]. In this study adherence was assessed by two indicators of dose adherence i.e. self report of missing of the drug doses and regular following of monthly dispense schedule. Follow up of dietary instruction was used as additional independent type of adherence.

The explanatory variables include sex, age, income, with whom client lives, marital status, household size, level of education, occupation, food source, treatment regimen and co-management of coinfections, socio-cultural factors like avoiding people because of HIV status, religion, ethnicity, psychiatric problems like depression, health care facility and health care providers, patient behavioral factors like HIV status disclosure and substance abuse.

The Source population was all adult HIV and AIDS patients who started antiretroviral treatment and follow up in the Hospital during the study period. All adult HIV sero-positive subjects started on ARV treatment and on follow up who were recruited in the study during the study period. The sample size of the study was 361 .

Concerning Sampling procedure Patients on follow up at ART treatment and care clinic meeting the inclusion criteria were selected by using patient's register as a sampling frame and adequate sample size was collected by using systematic random sampling method until the required sample size obtained. The first case selected by lottery method and every $3^{\text {rd }}$ subject was taken as study subject. For absent and non responding cases the subject who came next was taken as a replacement case.

The inclusion criteria comprised of AIDS patients who were on ART treatment for at least one month and willing to participate in the study. The Exclusion Criteria was HIV/AIDS patients on regular follow up but who did not start ART and those patients who were in critical medical and mental illness Data were collected from the study population using a pre-tested structured questionnaire which was validated through face to face interviews in the local language. For data quality assurance: Properly designed and pre-tested questionnaire was used. Interviewers and data clerks were trained and closely supervised during data collection and entry; and double data entry was used to ensure data quality.

The data were entered into a pre-drafted coding sheet on Epi info software, version 3.5 .3 by two different data clerks. Binary logistic analysis with conditional method calculating odds ratios (OR) and 95\% Confidence Intervals (CI) was used to estimate the association between the dependent variable and independent variables. Statistical significance was set at $\alpha . \leq 0.05$. In an attempt to identify the relative effects of explanatory variables on the outcome variable multivariable analyses was applied.

The ethical approval and clearance for this research study was obtained from Jimma University College of Health Sciences Institutional Research Ethics Review Committee. At all levels, officials were contacted and permission from administrators was secured. All the necessary explanation about the purpose of the study and its procedures was explained with the assurance of confidentiality. Both written and verbal consent from the study participants was also secured.

\section{Results}

Out of total study subjects $54.3 \%$ (194), the respondents' ages ranged from 18 to70 years and those with in the age group 50-59 and above 60 years old were $6.4 \%$ and $1.7 \%$, respectively. The mean age of respondents was 34.7 with SD of 8.8 years. Two hundred and sixteen $(60.4 \%)$ of clients were protestant by religion followed by orthodox $34.5 \%$. Concerning ethnicity majority of respondents $(78.2 \%)$ was Wolaita. The mean family size of the study population was 4.5 with SD of 2 persons. About $73.7 \%$ of the subjects had less than 6 persons in their families.

Of the 300 subjects who had formal education, the majority (42.0\%) attended some primary education (grade1-8). One hundred eighty nine (52.9\%) of subjects were living with their partners the remaining $47.1 \%$ living with non partner members of the family or alone. Majority of respondents $(59.7 \%)$ were married. Two hundred and fifty four $(71.1 \%)$ of subjects were employed, but one hundred and three $(28.9 \%)$ were unemployed. Among unemployed housewives have higher proportion (56.3\%). Ninety two percent of respondents mainly purchased food for their consumption, $3.4 \%$ got their food from household farm and $3.4 \%$ from both household farm and by purchasing, $0.8 \%$ from NGO/ welfare. Despite low income and purchasing food for consumption most of subjects $(79.6 \%)$ were able to afford three meals in a day (Table $1)$.

The study subjects for income were only $285(79.83 \%$ of the 
Citation: Alagaw A, Godana W, Taha M, Dejene T (2013) Factors Associated with Antiretroviral Treatment Adherence among Adult Patients in Wolaita Soddo Hospital. J Trop Dis 1: 125. doi: 10.4172/2329-891X.1000125

Page 3 of 7

\begin{tabular}{|c|c|c|c|c|}
\hline Variable & & Adherent $(n=312)$ & Non adherent $(n=45)$ & Total \\
\hline & & Frequency (\%) & Frequency (\%) & Frequency (\%) \\
\hline \multirow{2}{*}{ Sex } & Male & $147(41.17)$ & $16(1.68)$ & $163(45.66)$ \\
\hline & Female & $165(46.22)$ & $29(8.12)$ & $194(54.34)$ \\
\hline \multirow[t]{6}{*}{ Age group } & $18-19$ & $1(0.28)$ & $0(0)$ & $1(0.28)$ \\
\hline & $20-29$ & $78(21.85)$ & $13(3.64)$ & $91(25.49)$ \\
\hline & $30-39$ & $144(40.34)$ & $21(5.88)$ & $165(46.22)$ \\
\hline & $40-49$ & $64(17.92)$ & $7(1.96)$ & $71(19.89)$ \\
\hline & $50-59$ & $20(5.6)$ & $3(0.84)$ & $23(6.44)$ \\
\hline & $60+$ & $5(1.4)$ & $1(0.28)$ & $6(1.68)$ \\
\hline \multirow{2}{*}{ Income $\mathrm{n}=285$} & $\leq 500$ & $132(46.32)$ & $17(5.96)$ & $149(52.28)$ \\
\hline & $>500$ & $117(41.05)$ & $19(6.67)$ & $136(47.71)$ \\
\hline \multirow{2}{*}{ Family size } & $\geq 5$ & $226(63.3)$ & $37(10.36)$ & $263(73.67)$ \\
\hline & $\geq 6$ & $86(24.09)$ & $8(2.24)$ & $94(26.33)$ \\
\hline \multirow{4}{*}{ Marital status } & Married & $190(53.22)$ & $23(6.44)$ & 213(59.66) \\
\hline & Single & $24(6.72)$ & $7(1.96)$ & $31(8.68)$ \\
\hline & Divorced & $35(9.8)$ & $4(1.12)$ & $39(10.92)$ \\
\hline & Widowed & $63(17.64)$ & $11(3.08)$ & $74(20.72)$ \\
\hline \multirow{2}{*}{ Live with } & Non Partner & 132(36.97) & $36(10.08)$ & $168(47.06)$ \\
\hline & Partner & $180(50.42)$ & $9(2.52)$ & $189(52.94)$ \\
\hline \multirow{4}{*}{ Educational status } & Illiterate & $48(13.44)$ & $9(2.52)$ & $57(15.96)$ \\
\hline & Primary & 136(38.09) & $14(3.92)$ & $150(42.01)$ \\
\hline & Secondary & $95(26.61)$ & $16(4.48)$ & $111(31.09)$ \\
\hline & Higher & $33(9.24)$ & $6(1.68)$ & $39(10.92)$ \\
\hline \multirow{2}{*}{ Occupation } & Unemployed & $91(25.49)$ & $12(3.36)$ & $103(28.85)$ \\
\hline & Employed & $221(61.9)$ & $33(9.24)$ & $254(71.15)$ \\
\hline \multirow{3}{*}{ Meal number } & One & $1(0.28)$ & $0(0)$ & $1(0.28)$ \\
\hline & Two & $62(17.36)$ & $10(2.8)$ & $72(20.18)$ \\
\hline & $\geq$ three & $249(69.74)$ & $35(9.80)$ & $284(79.55)$ \\
\hline \multirow{4}{*}{ Consumption food source } & Purchase & $286(80.11)$ & $44(12.34)$ & $330(92.43)$ \\
\hline & Household farm & $12(3.36)$ & $0(0)$ & $12(3.36)$ \\
\hline & Welfare/NGO & $3(0.84)$ & 0 & $3(0.84)$ \\
\hline & Purchase +household farm & $11(3.08)$ & $1(0.28)$ & $12(3.36)$ \\
\hline
\end{tabular}

Table 1: Basic Socio-demographic characteristics of PLWHA involved in the study, Wolaita Soddo Hospital, South Ethiopia, May 2012.

study subjects) the remaining $20.16 \%$ had no monthly income. The median income of the study subjects was 500.00 Et.birr per-month, with standard deviation of 5.28 birr per month (bpm). The minimum monthly income was $100.00 \mathrm{bpm}$ while maximum income was 4000.00 bpm.

The three adherences (self report of missed doses, Pharmacy refill records and dietary adherences) were assessed in the study. Accordingly, $312(87.4 \%)$ of the study subjects were adherent based on self-report of missed doses (dose adherence) in a one-week recall. Three hundred thirty two (93\%) of the study subjects were adherent to Pharmacy refill records. One hundred and fifty three $(42.9 \%)$ subjects had dietary or food adherence.

Most common management mentioned by subjects for inadequate diet was taking drug in empty stomach (96.1\% of cases). But $3.4 \%$ avoid taking drugs and $0.5 \%$ by extending the time of taking drugs. Twenty nine percent of respondents were taking a FDC known as Triomune 30 \{Stavudine (dt4), Lamivudine (3TC) and Nevirapine (NVP)\}. Triomune 30 regimen was recommended for respondents who were below $60 \mathrm{~kg}$ body weight. Only two $(0.6 \%)$ of clients were taking Fixed Dose Combination of ARV regimen D4T (30)+3TC+NVP (1a(30)) known as Nevilast 40 \{Stavudine (dt4), Lamivudine (3TC) and Nevirapine (NVP)\}. Nevilast 40 regimen was recommended for respondents who were above $60 \mathrm{~kg}$ body weight. Currently the recommendation is to shift patients on Nevilast 40 to triammune 30 . Nineteen percent of clients were taking TDF+3TC+EFV, $16.5 \%$ were taking AZT+3TC+NVP, 13.2\% were taking AZT+3TC+EFV, $13.2 \%$ were taking $\mathrm{TDF}+3 \mathrm{TC}+\mathrm{NVP}, 6.2 \%$ were taking $\mathrm{D} 4 \mathrm{~T}+3 \mathrm{TC}+\mathrm{EFV}$. Relatively higher proportion of patients who missed ART was among the groups on D4T+3TC+EFV (18.2\%). Fourteen (14.5\%) missed TDF3TC-EFV, thirteen (12.5\%) missed AZT-3TC- NVP) (Table 2).

Out of $12.6 \%$ of respondents who failed to adhere to self reported dose, the main reason for missing a drug dose was forgetting $(48.9 \%)$. Stock finished accounted for $15.6 \%, 11.1 \%$ said they missed because of lack of transport cost, being too ill and lack of food to take with drugs each accounted for $2.2 \%$ of reasons for missing to take ARV drugs, and other reasons $(11.1 \%)$. This showed that respondents had various reasons that made them miss treatment doses. Majority of respondents 99.4\% said that government health facilities are the only source of ARV drugs. Two patients $(0.7 \%)$ said they got ART drugs from friends, relatives and from private health facility in case their ARV drugs get finished. This finding indicated that majority of respondents were aware of where they should get their ARV medication timely.

Most of the client (88.5\%) disclosed their HIV status. Non adherence among those who disclosed their status was $11.07 \%$ while 
Citation: Alagaw A, Godana W, Taha M, Dejene T (2013) Factors Associated with Antiretroviral Treatment Adherence among Adult Patients in Wolaita Soddo Hospital. J Trop Dis 1: 125. doi: 10.4172/2329-891X.1000125

Page 4 of 7

\begin{tabular}{|c|c|c|c|c|}
\hline Variables & & Adherent(312) & Non adherent(45) & Total (357) \\
\hline \multirow{5}{*}{ ART drug used for } & Cure & $23(6.44)$ & $7(1.96)$ & $30(8.4)$ \\
\hline & Reducing pain & 162(45.37) & $23(6.44)$ & $185(51.82)$ \\
\hline & Reduce progression of HIV & $73(20.45)$ & $5(1.4)$ & $78(21.85)$ \\
\hline & Don't know & $0(0)$ & $1(0.28)$ & $1(0.28)$ \\
\hline & $\begin{array}{c}\text { Reducing pain and progression } \\
\text { of HIV }\end{array}$ & $54(15.12)$ & $9(2.52)$ & $63(17.64)$ \\
\hline \multirow{11}{*}{ Type of ART used } & D4T-3TC-NVP(30) & $90(25.2)$ & $14(3.92)$ & $104(29.13)$ \\
\hline & D4T-3TC-NVP(40) & $2(0.56)$ & 0 & $2(0.56)$ \\
\hline & D4T-3TC-EFV(1b30) & $18(5.04)$ & $4(1.12)$ & $22(6.16)$ \\
\hline & AZT-3TC-NVP(1C) & $53(14.8)$ & $6(1.68)$ & $59(16.52)$ \\
\hline & AZT-3TC-EFV(1D) & $40(11.2)$ & $7(1.96)$ & $47(13.17)$ \\
\hline & ABC-DDI-LPV/t(2a) & $2(0.56)$ & 0 & $2(0.56)$ \\
\hline & TDF-DDI-LPV/R(2c) & $1(0.28)$ & 0 & $1(0.28)$ \\
\hline & TDF-DDI-NFV(2d) & $1(0.28)$ & 0 & $1(0.28)$ \\
\hline & TDF-3TC-NVP & $41(11.48)$ & $7(1.96)$ & $48(13.44)$ \\
\hline & TDF-3TC-EFV & $62(17.37)$ & $7(1.96)$ & 69(19.32) \\
\hline & TDF-3TC-LPV/r & $2(0.56)$ & 0 & $2(0.56)$ \\
\hline \multirow[t]{7}{*}{ Reason for missing ART } & Toxicity & $0(0)$ & $4(1.12)$ & $4(1.12)$ \\
\hline & Forgetting & $0(0)$ & $22(6.16)$ & $22(6.16)$ \\
\hline & Too ill & 0 & $1(0.28)$ & $1(0.28)$ \\
\hline & Stock finished & 0 & $7(1.96)$ & $7(1.96)$ \\
\hline & Lack of transport cost & 0 & $5(1.4)$ & $5(1.4)$ \\
\hline & Lack of food to take with drugs & 0 & $1(0.28)$ & $1(0.28)$ \\
\hline & Others & 0 & $5(1.4)$ & $5(1.4)$ \\
\hline \multirow{5}{*}{ Non ART drugs used by subjects } & Pain killers & 0 & $1(0.28)$ & $1(0.28)$ \\
\hline & Appetizers & $2(0.56)$ & 0 & $2(0.56)$ \\
\hline & Anti TB drugs & $11(3.08)$ & $2(0.56)$ & $13(3.64)$ \\
\hline & Antibiotics & $209(58.54)$ & $26(7.28)$ & $235(65.83)$ \\
\hline & Others & $1(0.28)$ & $1(0.28)$ & $2(0.56)$ \\
\hline
\end{tabular}

Table 2: Treatment related characteristics of PLWHA involved in the study, Wolaita Soddo Hospital, South Ethiopia, May, 2012.

\begin{tabular}{|c|c|c|c|c|}
\hline \multirow{2}{*}{ Variable } & & Adhered & Non-adhered & Total \\
\hline & & Frequency (\%) & Frequency (\%) & Frequency (\%) \\
\hline \multirow{4}{*}{ Substance abuse } & Alcohol & $2(0.56)$ & $1(0.28)$ & $3(0.84)$ \\
\hline & Kcat & $5(1.4)$ & $1(0.28)$ & $6(1.68)$ \\
\hline & Cigarette & $1(0.28)$ & 0 & $1(0.28)$ \\
\hline & Combined & $3(0.84)$ & 0 & $3(0.84)$ \\
\hline \multirow{2}{*}{ Disclosed HIV status } & Yes & $281(78.71)$ & $35(9.8)$ & $316(88.52)$ \\
\hline & No & $31(8.68)$ & $10(2.8)$ & $41(11.48)$ \\
\hline \multirow{2}{*}{ Inadequate diet to take with $\mathrm{ART}$} & Yes & $171(47.9)$ & $33(9.24)$ & $204(57.14)$ \\
\hline & No & $141(39.5)$ & $12(33.6)$ & $153(42.86)$ \\
\hline \multirow{5}{*}{$\begin{array}{l}\text { How food scarcity managed } \\
\text { Opinion to ART }\end{array}$} & By avoiding taking drugs & $5(1.4)$ & $2(0.56)$ & $7(1.96)$ \\
\hline & Prolonging time of taking drugs & $167(46.78)$ & $30(8.4)$ & $197(55.2)$ \\
\hline & Approve & $308(86.27)$ & $44(12.32)$ & $352(98.6)$ \\
\hline & Disagree & $4(1.12)$ & 0 & $4(1.12)$ \\
\hline & Undecided & 0 & $1(0.28)$ & $1(0.28)$ \\
\hline \multirow{2}{*}{ Subject supported for adherence } & Yes & $186(52.1)$ & $13(3.64)$ & 199(55.74) \\
\hline & No & $126(35.3)$ & $32(8.96)$ & $158(44.26)$ \\
\hline \multirow{2}{*}{ Depression } & Yes & $84(23.53)$ & $22(6.16)$ & $106(29.7)$ \\
\hline & No & $228(63.86)$ & $23(6.44)$ & $251(70.3)$ \\
\hline \multirow{5}{*}{ Who supported for adherence } & Spouse & $91(25.49)$ & $4(1.12)$ & $95(26.6)$ \\
\hline & Immediate member of family & $88(24.65)$ & 9 & $97(27.17)$ \\
\hline & Nurse & $4(1.12)$ & 0 & $4(1.12)$ \\
\hline & Doctor & $2(0.56)$ & 0 & $2(0.56)$ \\
\hline & Other & $1(0.28)$ & 0 & $1(0.28)$ \\
\hline
\end{tabular}

Table 3: Personal behavior factors. 
among who did not disclose was $24.4 \%$. Three hundred forty four (96.4\%) of subjects were free of any substance abuse but $1.7 \%$ use kcat, $0.8 \%$ alcohol, $0.3 \%$ cigarette and $0.8 \%$ use the above substances in some combination. Twelve (92.3\%) of substance users were males and only $7.7 \%$ of users was female. There was no significant association between substance use and ART adherence status.

Most respondents $65.8 \%$ were undergoing treatment of both HIV and antibiotics, $3.6 \%$ were undergoing co-treatment of HIV and TB, $0.6 \%$ was on treatment with appetizers and $0.3 \%$ was being treated with painkillers. As most patients were on prophylactic antibiotic which is once daily dose, pill burden was not complained by study subjects. There was no statistically significant association between ART adherence status and pill burden (co-treatment of other problems.

One hundred and six (29.7\%) of clients had depression, $70.3 \%$ no depression. Adherence among depressed groups was $79.24 \%$ but among non depressed groups was $90.83 \%$. Three hundred and fifty four $(99.2 \%)$ of clients received counseling, $0.8 \%$ said they were not counseled. All the clients said counseling is important for ART adherence and all the subjects satisfied that privacy was maintained during clinic visit and during special consultation of health professionals. One hundred and ninety nine (55.7\%) of clients have some supporter for ART adherence, $44.3 \%$ didn't have supporter of adherence (Table 3).

Non-adherent patients and those who had been adherent were compared on key demographic, health, mental health, and social factors. Results of bivariate logistic regression analyses showed that from sociodemographic variables with whom a subject lives i.e., with a partner or non partner was statistically significantly associated with adherence status $(\mathrm{OR}=1.916(1.017-3.608) \quad \mathrm{P}<0.001$. Other socio-demographic variables with a p-value of 0.25 to be included in multivariate analysis include sex of the subject (OR 1.615(0.843-3.092) $\mathrm{P}=0.148$ ), family size of the subject (OR 1.760(0.788-3.931), $\mathrm{P}=0.168$ ), and consumption food source ( $\mathrm{OR}=0.250(0.033-1.889) \mathrm{P}=0.179)$ (Table 4).

In bivariate analysis of treatment related, personal behavior, clinical, and health service related characteristics of the study subjects were associated with ART adherence status. Variables statistically significantly associated adherence status include HIV status disclosure (OR 2.590(1.17-5.73) $\mathrm{P}=0.019)$ ), depression (OR 2.596(1.375-4.903)
$\mathrm{P}=0.003)$ ), having inadequate diet to take with ART ( $\mathrm{OR}=2.268$ (1.129, 4.554), $\mathrm{P}=0.021$ ) and having adherence support (OR 3.634(1.8357.195) $\mathrm{P}=0.001)$ ).

Variables entered in multivariate analysis were: adherence supporter, sex of the subject, with whom a subject lives, depression, food source of the subject, inadequate diet to take with ART, family size, and HIV disclosure status of the subject. Multivariate logistic regression showed that inadequate diet to take with ART (AOR=2.229(1.034-4.807)), depression, and with whom a subject lives were statistically significantly associated with ART adherence. Disclosure of HIV status, food source of the subject, having or not having adherence support which were significant in bivariate analysis were not statistically significant in multivariate analysis which may be due to confounding effect of other variables.

\section{Discussions}

In this study, the adherence to ART is good. The following are associated with ART adherence. Food scarcity to take with ART, source of food for consumption, with who subject lives and depression status, Participants' self-reports of adherence in this study indicated suboptimal dose adherence (87.5\%) and an acceptable degree of monthly dispense adherence (93\%), while very low adherence to dietary instructions (42.9\%) in comparison with the required $95 \%$ adherence. Subjects were more adherent to monthly dispensing appointments this may be because they have remainder cards for monthly appointments. But were least adherent to dietary requirements may be because of low socioeconomic status (Median monthly income was 500.00Etbpm with $\mathrm{SD}$ of $5.28 \mathrm{bpm})$.

As mentioned above the rate of dose adherence in the study area was (87.5\%) which is higher than that reported in Addis Ababa $(81.2 \%$ and $82.8 \%)[16,17]$. This may suggest that adherence in regional setting is better than central settings and that patients of low socioeconomic status were able to achieve excellent rates of adherence with ART. Only one quarter of the Addis Ababa study population reported income of less than 500 birr per month [16] whereas more than $50 \%$ of this study population earned less than 500 birr per month. Consistent findings were also documented in comparable studies in resource limited settings in the sub-Saharan Africa [18].

\begin{tabular}{|c|c|c|c|c|c|}
\hline Variable & & Missed & veek & & \\
\hline & & No & Yes & Crude & Adjusted \\
\hline Sex of client & Male & 147 & 16 & $1.615(0.843-3.092)$ & $1.058(0.509-2.196)$ \\
\hline & Female & 165 & 29 & & \\
\hline HIV disclosure & No & 31 & 10 & $2.590(1.17-5.73)$ & $0.647(0.247-1.698)$ \\
\hline Hiv aisciosure & Yes & 281 & 35 & & \\
\hline Denreccion ctatuc & No & 228 & 23 & & \\
\hline Depressivit status & Yes & 84 & 22 & $2.596(1.375-4.903)$ & $2.221(1.093-4.515)$ \\
\hline Sunnorted for adhorence & No & 126 & 32 & $3.634(1.835-7.195)$ & $0.523(0.233-1.171)$ \\
\hline supported tor adnerence & Yes & 186 & 13 & & \\
\hline & Partner & 182 & 19 & & \\
\hline suoject ive witn & Non partener & 130 & 26 & $1.916(1.017-3.608)$ & $4.943(2.168-11.27)$ \\
\hline Eond cource & Only purchase & 286 & 44 & & \\
\hline rood source & Others & 26 & 1 & $0.250(0.033-1.889)$ & $4.561(0.558-37.259)$ \\
\hline Fond ccarcity to take with $\mathrm{ART}$ & Yes & 171 & 33 & $2.268(1.129-4.554)$ & $2.229(1.034-4.807)$ \\
\hline r Uou scalcily lo lake vilut Ant & No & 141 & 12 & & \\
\hline 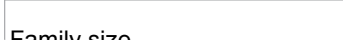 & $\leq 5$ & 226 & 37 & & \\
\hline ramily size & $\geq 6$ & 86 & 8 & $1.76(0.788-3.931)$ & $1.046(0.436-2.507)$ \\
\hline
\end{tabular}

Table 4: Summary of the logistic regression analysis of the effects of socioeconomic, demographic, clinical and behavioral factors that affect ART adherence, Wolaita Sddo Hospital, south Ethiopia, May, 2012. 
The self reported dose adherence rate found by this study was 87.5\%. It was less than the finding in Jimma University Specialized hospital and study in Kenya, Mombassa where self reported adherence was $93.4 \%$ and greater than $95 \%$, respectively $[12,19]$. Adherence rate in most developed countries, ranged from $50 \%$ to $70 \%$ [1,18]. Orrell et al. [18] also found that low socio economic status was not a predictor of adherence for patients with fully subsidized therapy and concluded that adherence in developing countries has been found to be at least as good as adherence in developed countries.

Among female respondents $85 \%$ adhered to ART while among the male respondents $90.18 \%$ adhered to treatment by direct interview indicating that there is slight difference in ART adherence with higher rate in males. This may be because females have burden of routine daily household activities which contributed to forgetting. Also study done on Canadian injection drug users showed that after adjusting for clinical characteristics as well as drug use patterns measured longitudinally throughout follow-up, female gender was independently associated with a lower likelihood of being $95 \%$ adherent to ART.

Depression was statistically significantly associated with adherence. Subjects with no depression have 2.596 times more adherent than those with depression. In other studies, in Kenya and South Africa, depression has been an important predictor of adherence [20,21]. These findings support a role for HIV/AIDS providers/counselors in screening for depression and providing treatment when appropriate, either directly or through collaboration with mental health professionals.

Patients who reported to have adherence support were 3.634 times more likely to be adherent than those who do not have adherence supporter. This finding suggests that lack of adequate diet influenced the qualitative aspect of ART adherence as most respondents managed their inadequate diet by taking drugs even when they didn't have diet. Inadequate diet to take with ART was significantly associated with dose adherence; similarly a study in South Africa showed that food supplement and higher CD4 cell count have statistical association with adherence [19].

With whom a subject lives was an independent predictor of adherence also studies in south Africa found that patients who were likely to be non-adherent were unmarried or lived alone, had poor social support, were reluctant to disclose and consumed alcohol [21]. The use of family members and peers to enhance ART adherence has emphasized the importance of social support in the treatment of HIV patients. Social support may enhance adherence through encouragement, reassurance, reinforcement, systematic cues, boastering of competence, and motivation, or by masking the effect of stress, anxiety, and depression [16].

Other variables like knowledge of ART benefit, knowledge on ART, and adherence knowledge which were significant predictors of adherence in other studies did not show association with adherence in this study. This may be because despite patients knowing the benefits of ART and the importance of adherence there were other factors like fear of stigma, low economic status that may mask the effect of the knowledge. This finding was supported by a study on HIV-patients in Lusaka Zambia who used to skip treatment doses due to lack of food [18].

In this study patients have high level of acceptance towards ART and there was low level of unacceptable behaviors for ART adherence like substance abuse which may contributed to an acceptable level of adherence found in the study. Also other studies shown that patient's behavior is the critical link between a prescribed regimen and treatment outcomes. Consequently, the most important factors influencing adherence are patient related and under the patient's control, so attention to them is a necessary and important step in improving adherence [22]. The limitation of the study, Recall bias- was the possible limitation of this self reported study to minimize it recent short duration (one week) period used. Over estimation of adherence during self report was another limitation and Absence of prior studies to estimate the proportion of adherent subjects which was approximated by national reports and figures from other studies in similar setting.

In conclusion level of adherence among the study participants was good. This could be explained by the fact that majority of the patients were positive about the aspects of care related to the ART clinic, interpersonal relationship with their care providers and their treatment plan plus being knowledgeable about HIV/AIDS

On top of their infection which predispose to different infections and low productivity, the study subjects have low income with a need to involve them in capacity building activities through collaboration with different stakeholders.

Psychosocial factors were the predominant factors affecting ART adherence. The findings emphasized the importance of multiple periodic assessments of adherence problems especially reasons for forgetting to take ART drugs. Timely detection of non-adherence behaviors and appropriate monitoring of patients' difficulties with HAART could potentially help patients to maintain adherence and therefore improve the treatment outcome. Finally the results suggested that psychosocial and medical interventions aimed at increasing adherence of HAARTtreated patients should integrate the dynamic dimensions of adherence behaviors.

\section{References}

1. Annual Performance Report of HSDP-III (2009) Ministry of Health, Federal Democratic Republic of Ethiopia.

2. Health and Health Related Indicators (1999) Federal Ministry of Health Planning and Programming.

3. AIDS Epidemic Update (2003) UNAIDS, World Health Organization. Geneva.

4. Samuel Sendagala (2010) Factors Affecting the Adherence to Antiretrovira Therapy by HIV Positive Patients Treated in a Community Based HIVIAIDS Care Programme in Rural Uganda: A Case of Tororo District, University Of South Africa.

5. Adherence to HIV Treatment. Geneva, Switzerland. World Health Organization 2004.

6. Bonolo Pde F, César CC, Acúrcio FA Ceccato Md, de Pádua CA et al. (2005) Non-adherence among patients initiating antiretroviral therapy: a challenge for health professionals in Brazil. AIDS 19: S5-S13.

7. Nachega JB, Stein DM, Lehman DA, Hlatshwayo D, Mothopeng R, et al. (2004) Adherence to antiretroviral therapy in HIV-infected adults in Soweto, South Africa. AIDS Res Hum Retroviruses 20: 1053-1056.

8. Ammassari A, Trotta MP, Murri R, Castelli F, Narciso P, et al. (2002) Correlates and predictors of adherence to highly active antiretroviral therapy: overview of published literature. J Acquir Immune Defic Syndr 31: S123-S127.

9. Eliud Wekesa (2007) ART adherence in resource poor settings in sub-Saharan Africa: a multidisciplinary review.

10. HIVIAIDS in Ethiopia -An Epidemiological Synthesis (2008) Ethiopia HIVIAIDS Prevention \& Control Office (HAPCO) and Global HIVIAIDS Monitoring and Evaluation Team (GAMET).

11. Nyambura Anthony Wanjohi (2009) Factors That Influence Non-Adherence To Antiretroviral Therapy Among Hiv And Aids Patients In Central Province, Kenya.

12. Amberbir A, Woldemichael K, Getachew S, Girma B, Deribe K (2008) Predictors of adherence to antiretroviral therapy among HIV-infected persons: a prospective study in Southwest Ethiopia. BMC Public Health 8: 265. 
Citation: Alagaw A, Godana W, Taha M, Dejene T (2013) Factors Associated with Antiretroviral Treatment Adherence among Adult Patients in Wolaita Soddo Hospital. J Trop Dis 1: 125. doi: 10.4172/2329-891X.1000125

Page 7 of 7

13. Mekonnen Y, Sanders E, Messele T, Wolday D, Dorigo-Zestma W, et al. (2005) Prevalence and incidence of, and risk factors for, HIV-1 infection among factory workers in Ethiopia, 1997-2001. J Health Popul Nutr 23: 358-368.

14. Chesney MA (2000) Factors affecting adherence to antiretroviral therapy. Clin Infect Dis 30 Suppl 2: S171-176.

15. Arnsten JH, Demas PA, Farzadegan H, Grant RW, Gourevitch MN, et al. (2001) Antiretroviral therapy adherence and viral suppression in HIV-infected drug users: comparison of self-report and electronic monitoring. Clin Infect Dis 33: 1417-1423.

16. Tadios Y, Davey G (2006) Antiretroviral treatment adherence and its correlates in Addis Ababa, Ethiopia. Ethiop Med J 44: 237-244.

17. Chishimba S and Zulu F (2004) The 3 X 5 HIVIAIDS Treatment plan; Challenges for developing countries from the Zambian perspective.
18. Orrell C, Bangsberg DR, Badri M, Wood R (2003) Adherence is not a barrier to successful antiretroviral therapy in South Africa. AIDS 17: 1369-1375.

19. Poppa A, Davidson O, Deutsch J, Godfrey D, Fisher M, et al. (2004) British HIV Association (BHIVA)/British Association for Sexual Health and HIV $(\mathrm{BASHH})$ guidelines on provision of adherence support to individuals receiving antiretroviral therapy (2003). HIV Med 5: 46-60.

20. Sarna A, Luchters S, Geibel S, Munyao P, Kaai S (2005) Promoting adherence to antiretroviral therapy through a directly administered antiretroviral therapy (DAART) strategy in Mombassa Kenya, Horizons Research Update. Nairobi.

21. Ekanem Esu Williams (2007) A Study on Social Support and ART Adherence at Carletonville Hospital and Zola Clinic in Gauteng Province. South Africa.

22. Michaels D, Darder M, Boulle A (2005) Determinants of short and long-term adherence to antiretroviral treatment in resource- poor settings. 